\title{
Pengaruh Lingkungan Keluarga Terhadap Pemenuhan Hak Bermain dan Hak Rekreasi
}

\author{
Nurul Aida Lestari ${ }^{\bowtie}$, Edi Waluyo ${ }^{2}$ \\ Pendidikan Guru Pendidikan Anak Usia Dini, Universitas Negeri Semarang, Indonesia(1) \\ DOI: $\underline{10.31004 / \text { obsesi.v6i3.1180 }}$
}

\begin{abstract}
Abstrak
Keluarga Sejahtera terbagi atas keluarga pra sejahtera, keluarga sejahtera 1, keluarga sejahtera 2, keluarga sejahtera 3, dan keluarga sejahtera 3 plus. Keluarga yang bisa mencukupi kebutuhan dasar, tapi belum bisa mencukupi kebutuhan sosial psikologisnya disebut keluarga sejahtera 1. Penelitian ini bertujuan untuk mengetahui terdapat tidaknya pengaruh lingkungan Keluarga Sejahtera 1 (KS-1) terhadap pemenuhan hak bermain dan hak rekreasi di Kecamatan Dukuhseti, serta untuk mengetahui faktor pendukung dan penghambat pemenuhan hak bermain dan hak rekreasi di Kecamatan Dukuhseti. Menggunakan metode penelitian kuantitatif analisis regresi linier sederhana dengan melakukan dua kali pengujian terhadap variabel bebas. Hasil penelitian menunjukkan bahwa terdapat pengaruh lingkungan KS-1 terhadap pemenuhan hak bermain dan hak rekreasi pada anak. Adapun faktor penghambat lingkungan KS-I terhadap pemenuhan hak bermain dan hak rekreasi meliputi: cara orang tua mendidik, kondisi ekonomi orang tua, dan latar belakang kebudayaan. Sedangkan faktor pendukung meliputi: interaksi antar anggota keluarga, suasana rumah, dan perhatian orang tua.
\end{abstract}

Kata Kunci : anak usia dini; hak bermain; hak rekreasi; lingkungan KS-1

\begin{abstract}
Prosperous familiy according to the $\mathrm{BKKBN}$ are divided into pre-prosperous families, prosperous families 1 , prosperous families 2 , prosperous families 3 , and prosperous families 3 plus. A family that can fulfill basic needs, but not yet able to fulfill their social and psychological needs is called a prosperous families 1 . This research aims to see the effect of the KS-1 environment on the fulfillment of playing rights and recreation rights in Dukuhseti District, and to determine the supporting and inhibiting factors for the fulfillment of the right to playing and recreation rights in Dukuhseti District. The method of the research uses quantitative method with simple linear regression analysis by conducting two tests on the independent variable as survey research. The conclusion that can be taken is that the KS-1 environment can provide the fulfillment of basic rights to play and the recreation rights for children. KS-I's environmental inhibiting factors for the fulfillment of play and recreation rights include: the way parents educate, the economic condition of the parents, and cultural background. While supporting factors include: interaction between family members, home atmosphere, and parents' attention.
\end{abstract}

Keywords: early childhood; play rights; recreational rights; KS-1's environment

Copyright (c) 2021 Nurul Aida Lestari, Edi Waluyo

$\triangle$ Corresponding author:

Email Address: nurulaidales@students.unnes.ac.id (Semarang, Indonesia)

Received 6 March 2021, Accepted 8 April 2021, Published 18 August 2021 


\section{PENDAHULUAN}

Anak sebagai potensi bagi pembangunan daerah yang memiliki hak untuk hidup, hak untuk berkembang, hak berpartisipasi sesuai harkat dan martabat kemanusiaan yang perlu dilindungi dari kekerasan dan diskriminasi (KEMENPPPA, 2020). Sesuai dengan UndangUndang Republik Indonesia Nomor 20 Tahun 2003 tentang Sistem Pendidikan Nasional pada pasal 1 ayat 14, disebutkan bahwa anak usia dini adalah anak usia 0-6 tahun. Total penduduk Indonesia mencapai 258 juta jiwa pada tahun 2016, sepertiga diantaranya sebanyak 32,24\% merupakan anak usia 0-17 tahun (Kementerian Pemberdayaan Perempuan dan Perlindungan Anak dan Badan Pusat Statistik, 2019).

Komite Hak Anak menyambut baik pengenalan tindakan hak anak sebagai mekanisme yang bisa memberikan efek hukum terhadap serangkaian hak dan prinsip yang dinyatakan dalam United Nations Convention on the Rights of the Child (UNCRC) tanggal 20 November 1989 dan berlaku pada 2 September 1990. UNCRC telah ditandatangi oleh 193 negara anggota PBB, kecuali dua negara yaitu Amerika Serikat dan Somalia. Terdapat 54 pasal dalam United Nations Convention on the Rights of the Child (UNCRC). Pasal 1-42 diantaranya terkait hak atas kelangsungan hidup dan berkembang; hak untuk hidup dengan orang tua; hak untuk bermain dan berkreasi; dan hak untuk memperoleh pendidikan dasar. Sedangkan pada pasal 43-54 berisi kerjasama yang bisa dilakukan orang dewasa dan pemerintah agar hak-hak semua anak dapat terpenuhi. Dalam Konvensi Hak Anak juga disebutkan prinsip umum sebagai sarana untuk mempelajari, menghormati, melindungi sehingga memungkinkan anak tumbuh dan berkembang secara optimal (UNICEF, 2018).

Indonesia, berdasarkan Keputusan Presiden No. 36 Tahun 1990, Konvensi Hak Anak (KHA) telah diratifikasi oleh Pemerintah Indonesia. Bentuk komitmen pemerintah Indonesia melalui Undang-Undang Nomor 23 Tahun 2002 yang kemudian mengalami perubahan menjadi Undang-Undang Nomor 35 Tahun 2014 mengenai perlindungan anak menyebutkan bahwa masing-masing anak berhak atas perlindungan dari kekerasan dan diskriminasi, kelangsungan hidup, berkembang dan tumbuh (Dewi, 2011). Bentuk komitmen lain ditunjukkan dengan adanya Kementerian Pemberdayaan Perempuan dan Perlindungan Anak sebagai kementerian yang membidangi urusan pemberdayaan perempuan dan perlindungan anak (KEMENPPPA, 2020). Kemudian, salah satu program pemerintah Indonesia dalam pemenuhan hak anak yaitu melalui KLA (Kabupaten Layak Anak). Kabupaten Layak Anak merupakan kabupaten/kota yang memiliki sistem pembangunan berbasis hak anak melalui pengintegrasian komitmen dan sumberdaya pemerintah, masyarakat dan dunia usaha yang terencana secara menyeluruh dan berkelanjutan dalam kebijakan, program dan kegiatan untuk untuk menjamin terpenuhinya hak anak (Sulistiowati dkk.,2018). Namun keberadaan sederhana instrumen semacam itu sejauh ini tidak ada jaminan untuk pemenuhan hak-hak anak (Indriati et al., 2018).

Kabupaten Pati terdiri dari 21 kecamatan, salah satu kecamatan yang menjadi sorotan dalam penelitian ini adalah Kecamatan Dukuhseti. Kecamatan Dukuhseti adalah kecamatan yang terletak paling utara, yang berbatasan langsung dengan Kabupaten Jepara dan Laut Jawa, berjarak kurang lebih $36 \mathrm{~km}$ kearah utara dari pusat Kota Pati. Kecamatan Dukuhseti terdiri dari 12 desa yaitu Wedusan, Grogolan, Dumpil, Bakalan, Ngagel, Kenanti, Alasdowo, Banyutowo, Dukuhseti, Kembang, Tegalombo, dan Puncel. Jumlah penduduk usia 0-14 tahun di Kecamatan Dukuhseti menurut sumber BPS Kabupaten Pati, Proyeksi Sensus Penduduk 2010 sebanyak 13.126 jiwa (Badan Pusat Statistik Kabupaten Pati, 2019) dan mempunyai 18 lembaga TK, 17 lembaga RA, serta 15 KB (KEMDIKBUD, 2019).

Berdasarkan tatanan sosial kemasyarakatan terdapat ukuran di dalam tingkatan masyarakat yang dikenal dengan stratifikasi sosial diantaranya adalah tingkat kesejahteraan keluarga yang dibagi dalam 3 tingkat, yaitu: pra keluarga sejahtera, keluarga sejahtera I (KS1), dan keluarga sejahtera (Badan Pusat Statistik Kabupaten Pati, 2019). Pada penelitian ini, peneliti fokus pada lingkungan keluarga sejahtera 1 (KS-1) karena berdasarkan tabel tahapan Keluarga Sejahtera di Kecamatan Dukuhseti, tahun 2016-2018 dapat diperoleh data bahwa 
Kecamatan Dukuhseti jumlah KS-1 mengalami kenaikan yang signifikan sebanyak 1.603 pada tahun 2018. Sebagian besar KS-1 bekerja sebagai nelayan dan petani. Diperoleh enam indikator tingkatan KS-I atau indikator kebutuhan dasar keluarga (basic need) meliputi: setiap keluarga makan dua kali sehari atau lebih; mempunyai pakaian yang beragam untuk bekerja/sekolah, di rumah dan bepergian; rumah yang ditempati memiliki dinding, atap, dan lantai yang layak; apabila terdapat anggota keluarga yang sakit diantar ke tempat pelayanan kesehatan; pergi ke pelayanan kontrasepsi apabila pasangan usia subur ingin $\mathrm{KB}$; serta seluruh anggota keluarga berusia 7-15 tahun sekolah (BKKBN, 2011).

Menurut Gunarsa (2008) lingkungan keluarga adalah lingkungan yang memberi pengaruh mendalam bagi anak. Adapun faktor-faktor lingkungan keluarga yang dikemukakan Slameto (2003) meliputi: cara orang tua mendidik, interaksi antar anggota keluarga, suasana rumah, kondisi ekonomi orang tua, perhatian orang tua, dan latar belakang kebudayaan. Lingkungan keluarga juga sebagai lingkungan utama yang berkewajiban untuk membentuk kasih sayang, kepribadian, bimbingan, perhatian, dan kesehatan (Barnadib, 2002). Keluarga yang ramah anak akan memberi dampak positif dalam mewujudkan pemenuhan hak-hak dasar anak (Shah et al., 2018). Berdasarkan rancangan dari Eaglantyne Jebb dalam Hidajat (2002) seorang aktivis hak anak merumuskan sepuluh butir hak-hak dasar anak yang kemudian diadopsi oleh PBB dalam UNCRC: 1) Hak bermain, 2) Hak untuk memperoleh pendidikan, 3) Hak untuk memperoleh perlindungan perlindungan, 4) Hak memperoleh nama atau identitas, 5) Hak untuk memperoleh status kebangsaan, 6) Hak untuk memperoleh makanan, 7) Hak untuk memperoleh akses kesehatan, 8) Hak mendapatkan rekreasi, 9) Hak memperoleh kesamaan, dan 10) Hak untuk berperan dalam pembangunan.

Dari ke-10 hak-hak dasar anak, terdapat 2 hak dasar anak di lingkungan KS-1 di Kecamatan Dukuhseti, Pati yang mayoritas belum dapat terpenuhi berdasarkan hasil wawancara sebagai studi awal penelitian dengan ketua PKK Kecamatan Dukuhseti yaitu hak bermain dan rekreasi. Menurut ketua PKK Kecamatan Dukuhseti, bermain dan rekreasi sangat penting dan saling terkait bagi anak usia dini. Belum terpenuhinya hak tersebut akibat kurangnya pengetahuan masyarakat tentang pemenuhan hak-hak dasar anak di lingkungan KS-I. Dengan adanya permasalahan di atas, terpilihnya hak bermain dan hak rekreasi sebagai hak-hak dasar anak yang akan diteliti.

Pada pemenuhan hak bermain, keluarga dihadapkan oleh persoalan minimnya ruang publik untuk tempat bermain anak, beban akademik dan terbatasnya waktu bermain yang mengurangi kebebasan anak mendapatkan hak bermain anak. Anak mempunyai jadwal yang padat setiap harinya. Setelah selesai sekolah pukul $10.00 \mathrm{WIB}$, dilanjutkan dengan les membaca pada pukul $11.00 \mathrm{WIB}$, dan anak-anak harus mengikuti TPQ pada sore hari. Sehingga, tersisa sedikit waktu untuk bermain, selain itu kurang adanya stimulasi dari orang tua saat menemani bermain dalam mengoptimalkan perkembangan anak padahal menurut Albert Einstein dalam Pratama, dkk (2016) bermain merupakan bentuk penelitian tertinggi bagi seorang anak. Singer dalam Kurnia (2012) menyebutkan, bermain adalah cara untuk melatih masuknya rangsangan, baik dari dunia luar maupun dari dalam yang dapat mengeskpresikan potensi kreatif anak.

Selanjutnya, pemenuhan hak anak dalam mendapatkan rekreasi. Rekreasi dapat meningkatkan pengetahuan anak, rasa percaya diri, mandiri, tanggungjawab, membiasakan diri beradaptasi dengan lingkungan baru, menghilangkan kejenuhan, membangun kebersamaan dalam keluarga, dan menjaga keharmonisan keluarga (Widyatama \& Suwena, 2017). Rekreasi memberikan pengalaman langsung kepada anak serta pembelajaran nyata. Anak belajar bukan hanya menggunakan buku tapi anak dapat belajar dari lingkungan luar, memperbaharui pemikiran anak dan meningkatkan minat belajar anak (Rosdiani, 2016). Namun, beberapa anak cenderung mendapatkan hak untuk rekreasi ketika ada program dari sekolah, selebihnya dalam lingkungan keluarga, hak mendapatkan rekreasi dianggap kurang penting (Babić et al., 2018). 
Menurut Slameto (2003) di dalam lingkungan keluarga terjadi interaksi antara anggota keluarga. Dapat dijabarkan pada tabel 1 faktor-faktor dalam lingkungan keluarga.

Tabel. 1 Faktor-Faktor Lingkungan Keluarga (Slameto, 2003)

\begin{tabular}{|c|c|c|}
\hline No. & Faktor & Penjabaran \\
\hline 1 & $\begin{array}{l}\text { Cara orang tua } \\
\text { mendidik }\end{array}$ & $\begin{array}{l}\text { Perhatian orang tua yang tidak optimal menjadi salah satu penyebab } \\
\text { stimulasi yang didapat anak tidak menyeluruh. Memberi kebebasan } \\
\text { pada anak merupakan salah satu pola asuh yang baik, anak akan } \\
\text { memilih sesuai dengan kemampuan dan keinginannya (Lehrl et al., } \\
\text { 2020). Tetapi, kebebasan ini tetap diiringi oleh bimbingan dan arahan. }\end{array}$ \\
\hline 2. & $\begin{array}{l}\text { Interaksi antar } \\
\text { anggota } \\
\text { keluarga }\end{array}$ & $\begin{array}{l}\text { Adanya interaksi dipengaruhi oleh individu, tujuan, dan kegiatan yang } \\
\text { sesuai di dalam lingkungan keluarga akan memberikan pemenuhan } \\
\text { kebutuhan anak semakin mudah dan dapat mengasah perkembangan } \\
\text { dengan optimal (Orth, 2018). }\end{array}$ \\
\hline 3. & Suasana rumah & $\begin{array}{l}\text { Suasana rumah merupakan keadaan yang dapat terjadi dalam } \\
\text { lingkungan keluarga. Anak dapat bnermain dan mempelajari keadaan } \\
\text { jika suasana rumah harmonis, tentram, dan tenang yang menyebabkan } \\
\text { akan menyukai rumah daripada tempat lain (Thalib, 2020) }\end{array}$ \\
\hline 4. & $\begin{array}{l}\text { Kondisi orang } \\
\text { tua }\end{array}$ & $\begin{array}{l}\text { Kondisi ekonomi orang tua memiliki pengaruh pada pemenuhan } \\
\text { kebutuhan anak. Keluarga menengah ke bawah akan kesulitan } \\
\text { memenuhi kebutuhan anak, kebutuhan anak tidak dapat terpenuhi } \\
\text { dengan maksimal. Tetapi, sebagian keluarga mampu mengubah kondisi } \\
\text { tersebut sebagai dorongan anak dalam mencapai keberhasilan yang } \\
\text { lebih baik dari kedua orantuanya. Segala keinginan anak terpenuhi tidak } \\
\text { menjamin kebahagian anak. Karena seorang anak membutuhkan kasih } \\
\text { sayang yang cukup dalam perkembangannya. }\end{array}$ \\
\hline 5. & $\begin{array}{l}\text { Perhatian } \\
\text { orang tua }\end{array}$ & $\begin{array}{l}\text { Perhatian dari orangtua sangat diperlukan oleh anak. Ketika anak } \\
\text { merasa dirinya gagal dalam menghadapi masalah, maka semangat dan } \\
\text { perhatian dari orang tua dapat menjadi senjata untuk bangkit kembali } \\
\text { menghadapi segala permasalahan yang ada. Orangtua akan selalu } \\
\text { memenuhi fungsi dan perannya sesuai dengan aspek perkembangan } \\
\text { anak baik kebutuhan fisik maupun non fisik demi tumbuh kembang } \\
\text { anak (Ali \& Prima, 2020) }\end{array}$ \\
\hline 6. & $\begin{array}{l}\text { Latar belakang } \\
\text { kebudayaan }\end{array}$ & $\begin{array}{l}\text { Kebudayaan menurut Dewantara dalam Ahmadi (2007) berarti buah } \\
\text { budi manusia adalah hasil dari usaha manusia, baik berupa material } \\
\text { maupun spiritual untuk mencukupi kebutuhan hidup. Kebudayaan } \\
\text { terbentuk dari interaksi sosial yang diwariskan kepada generasi muda } \\
\text { melalui pendidikan. Tingkat pendidikan dan kebiasaan orang tua } \\
\text { berpengaruh pada sikap anak. Anak harus diberi arahan tentang } \\
\text { kebiasaan baik sehingga memberi semangat kepada anak menjelajahi hal } \\
\text { baru sedini mungkin. }\end{array}$ \\
\hline
\end{tabular}

Untuk menguatkan latar belakang penelitian, penulis menelaah penelitian terdahulu dari Wardani \& Hasanah (2015) dalam jurnal Perempuan dan Anak dengan judul "Pemenuhan Hak Anak dalam Keluarga Poligami". Penelitian ini bertujuan untuk mendeskripsikan keluarga poligami dalam memenuhi hak anak. Menggunakan pendekatan dan metode kualitatif. Simpulan dari sebuah sukses dan pencapaian kebahagiaan dalam keluarga poligami yaitu ketika suami paham akan kewajiban keluarga terutama anak. Pernikahan monogami lebih membahagiakan dibanding dengan poligami. Keluarga monogami, seorang suami mampu melimpahkan seluruh perhatian dan emosinya kepada satu istri dan anak. Akan mudah bagi suami dalam pemenuhan hak istri dan anak, meliputi perhatian, kasih sayang dan kebutuhan material.

Berdasarkan hasil penelitian terdahulu, wawancara dengan ketua PKK, dan observasi awal penelitian maka, penelitian ini perlu dilakukan di lingkungan KS-1 dengan tujuan untuk mengetahui terdapat tidaknya pengaruh lingkungan KS-1 terhadap pemenuhan hak bermain 
dan hak rekreasi, serta mengetahui apa saja faktor pendukung dan penghambat pemenuhan hak bermain dan hak rekreasi bagi anak usia 3-6 tahun di lingkungan KS-1, Kecamatan Dukuhseti, Kabupaten Pati. Penting dilakukan penelitian ini karena lingkungan keluarga merupakan lingkungan pertama bagi anak usia dini dalam terpenuhi hak-hak dasar termasuk diantaranya hak bermain dan hak rekreasi.

\section{METODOLOGI}

Penelitian ini menggunakan pendekatan kuantitatif regresi linier sederhana dengan dua kali pengujian terhadap variabel bebas. Penelitian ini dibagi menjadi beberapa tahapan, yaitu: (1) Pra penelitian, yakni menyusun rancangan awal, pengurusan izin, observasi latar belakang, pemilihan variabel, metode penelitian dan pembuatan angket penelitian, uji coba instrumen (2) tahap pelaksanaan penelitian di lapangan, yakni melakukan pengamatan (observasi), melakukan penyebaran angket pada responden, dan mendokumentasikan data penelitian (3) pasca penelitian, melakukan tabulasi data, olah data dengan uji asumsi penelitian terlebih dahulu yaitu uji normalitas dan linieritas, kemudian baru diuji menggunakan metode kuantitatif regresi linier sederhana variabel $x$ dengan $y_{1}$ dan variabel $x$ dengan $y_{2}$. Alur kegiatan penelitian dapat digambarkan pada gambar 1.

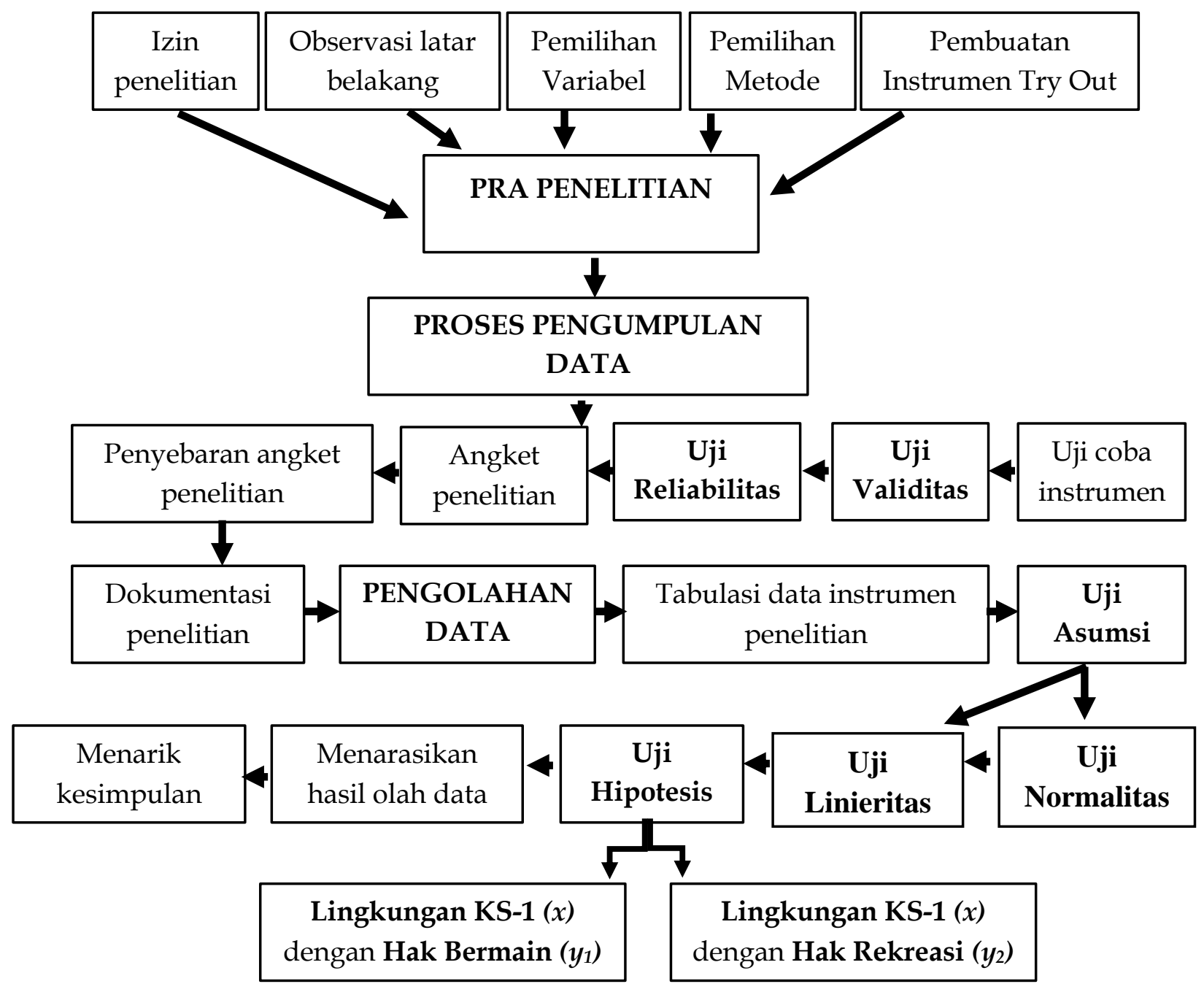

Gambar 1. Alur Pelaksanaan Penelitian

Penulis membuat angket tertutup sebanyak 90 item pernyataan, menggunakan skala likert dengan 4 opsi pilihan jawaban yang telah diuji coba kepada 33 responden KS-1 di 
kecamatan kontrol yakni Kecamatan Tayu karena sama memiliki kenaikan jumlah KS-1 pada data tahun 2018. Item dikatakan valid jika $r_{\text {hitung }}<r_{\text {tabel }}$ pada $\alpha=5 \%$, diperoleh $r_{\text {tabel }}=.344$ dari Person Product Moment. Sebanyak 71 item valid dan reliable. Hasil uji reliabilitas dapat dilihat pada tabel 2 Uji reliabilitas, sedangkan kisi-kisi instrumen penelitian dapat dilihat pada tabel 3 kisi-kisi instrumen penelitian.

Tabel 2. Uji Reliabilitas

\begin{tabular}{lccc}
\hline \multicolumn{1}{c}{ Keterangan } & Cronbach's Alpha & \multicolumn{2}{c}{$\begin{array}{c}\text { Cronbach's Alpha Based on } \\
\text { Standardized Items }\end{array}$} \\
\hline Lingkungan KS-1 & .824 & & .842 \\
Hak Bermain & .806 & & .838 \\
Hak Rekreasi & .707 & .671 \\
\hline
\end{tabular}

Tabel 3. Kisi-Kisi Instrumen Penelitian

\begin{tabular}{|c|c|c|c|c|c|}
\hline No & Variabel & Indikator & $\begin{array}{c}\text { Pernyataan } \\
\text { Favorabel }\end{array}$ & $\begin{array}{c}\text { Pertanyaan } \\
\text { Unfavorabel }\end{array}$ & Jumlah \\
\hline \multirow[t]{8}{*}{1} & Lingkungan & Cara Orang Tua & $1,2,3,4,5$ & 23 & 6 \\
\hline & Keluarga & Mendidik & & & \\
\hline & & $\begin{array}{l}\text { Interaksi antar } \\
\text { anggota keluarga }\end{array}$ & $7,8,9,10,11$ & 6,22 & 7 \\
\hline & & Suasana rumah & $12,13,14$ & 15 & 4 \\
\hline & & Perhatian orangtua & 16,17 & 21 & 3 \\
\hline & & Latar Belakang & $18,19,20$ & 24,25 & 5 \\
\hline & & Kebudayaan & & & \\
\hline & & & Total & & 25 \\
\hline \multirow[t]{8}{*}{2} & Hak Bermain & Intelegensi & $1,5,7,8,10,19$ & 22 & 7 \\
\hline & & Perkembangan motoric & 13,14 & - & 2 \\
\hline & & Kesehatan & 11,12 & 17 & 3 \\
\hline & & Jenis kelamin & 6,18 & - & 2 \\
\hline & & Lingkungan & $2,3,9$ & - & 3 \\
\hline & & Jumlah waktu bebas & 4,15 & 21 & 3 \\
\hline & & Alat permainan & 20,23 & 16 & 3 \\
\hline & & & Total & & 23 \\
\hline \multirow[t]{5}{*}{3} & Hak Rekreasi & Adaptasi & $3,4,16,23$ & 10 & 5 \\
\hline & & Kebersamaan & $\begin{array}{c}2,6,7,11,19 \\
22\end{array}$ & 9 & 7 \\
\hline & & Waktu luang & $12,13,15,18$ & 14,21 & 6 \\
\hline & & Kreatifitas & $1,5,8,17$ & 20 & 5 \\
\hline & & & Total & & 23 \\
\hline \multicolumn{3}{|c|}{ Total Pernyataan } & & & 71 butir \\
\hline
\end{tabular}

Menggunakan uji asumsi (uji normalitas dan linieritas) untuk memberikan kepastian bahwa persamaan regresi yang didapatkan memiliki ketepatan dalam estimasi, tidak bias dan konsisten. Sedangkan uji hipotesis menggunakan regresi linier sederhana yang dilakukan dua kali untuk menguji variabel $x$ dengan $y_{1}$ dan $x$ dengan $y_{2}$.

Populasi yang diambil adalah semua lingkungan KS-I di Kecamatan Dukuhseti. Teknik pengambilan sampel menggunakan purposive sampling yaitu penarikan sampel dari populasi yang mempunyai tujuan spesifik dari penelitian dengan kriteria usia 3-6 tahun dan tinggal bersama orangtua kandung. Sampel yang diambil oleh peneliti sebanyak 48 KS-I di 12 desa, Kecamatan Dukuhseti dapat dilihat pada tabel 4. Sampel berdasarkan jenis kelamin dan tabel 5. Sampel berdasarkan usia. 
Tabel 4. Sampel Berdasarkan Jenis Kelamin

\begin{tabular}{lcc}
\hline Jenis Kelamin & Frekuensi & Presentase \\
\hline Laki-laki & 19 & $39.583 \%$ \\
Perempuan & 29 & $60.417 \%$ \\
Total & 48 & $100 \%$
\end{tabular}

Tabel 5. Sampel Berdasarkan Usia

\begin{tabular}{lcc}
\hline \multicolumn{1}{c}{ Usia } & Frekuensi & Presentase \\
\hline 3-4 tahun & 22 & $45.83 \%$ \\
5-6 tahun & 26 & $54.17 \%$ \\
Total & 48 & $100 \%$ \\
\hline
\end{tabular}

Dasar analisis pengambilan keputusan penelitian yaitu jika $t_{\text {hitung }}>t_{\text {tabel }}$, maka $r_{x y}$ adalah signifikan dan jika $t_{\text {hitung }}<t_{\text {tabel }}$, maka $r_{x y}$ adalah tidak signifikan. Dapat juga menggunakan nilai Sig. apabila nilai Sig. $<.005$ berarti bahwa ada pengaruh antara $x$ terhadap $y_{1}$ dan $x$ terhadap $y_{2}$ maka $H_{01}$ dan $H_{02}$ ditolak dan begitu pula sebaliknya.

\section{HASIL DAN PEMBAHASAN}

Lingkungan keluarga secara umum dapat dijabarkan sebagai lingkungan yang memberi pengaruh utama terhadap tingkah laku dan perkembangan anak (Latiana, 2019). Selain itu, lingkungan keluarga juga merupakan lingkungan pertama bagi anak dalam memperoleh haknya (Nuryani, 2015), termasuk diantaranya hak bermain dan hak rekreasi. Lembaga yang dijadikan sampel penelitian adalah lingkungan KS-1 di Kecamatan Dukuhseti. Untuk memperoleh hasil dalam penelitian ini perlu melakukan uji prasyarat analisi sebelum melakukan uji hipotesis.

\section{Uji Prasyarat Analisis}

Pada instrumen penelitian disebutkan bahwa indikator variable lingkungan keluarga sejahtera 1 (KS-1), meliputi: cara orang tua mendidik, interaksi antar anggota keluarga, suasana rumah, perhatian orang tua, dan latar belakang kebudayaan. Indikator variabel hak bermain, meliputi: intelegensi, perkembangan motorik, kesehatan, jenis kelamin, lingkungan, jumlah waktu bebas, dan alat permainan. Indikator hak rekreasi, meliputi: adaptasi, kebersamaan, waktu luang, dan kreativitas. Masing-masing indikator disajikan dalam bentuk pernyataan favorable dan unfavorabel. Maka didapatkan tabel data hasil analisis dekriptif yang menggambarkan ringkasan data-data penelitian yang sudah dilaksanakan meliputi mean, minimum, dan maksimum dalam tabel6 data hasil analisis deskriptif. Analisis statistik deskriptif dari masing-masing variabel dalam penelitian ini dapat diketahui melalui tabel 7 distribusi frekuensi. Hasil uji asumsi didapakan dari penghitungan menggunakan uji normalitas dan uji linearitas yang dapat dilihat pada tabel 8. Uji normalitas dan tabel 9. Uji Linieritas.

Berdasarkan hasil uji normalitas variabel lingkungan KS-1 $(x)$ dengan variabel hak bermain $\left(y_{1}\right)$ diketahui $\alpha=.162>.05$ sedangkan variabel lingkungan KS-1 $(x)$ dengan variabel hak rekreasi $\left(y_{2}\right)$ diketahui $\alpha=.071>.05$ maka data berdistribusi normal.

Hasil uji linearitas variabel $x$ dengan $y_{1}$ diketahui Sig. deviation from linearity sebesar $.302>$ .05 sedangkan variabel $x$ dengan $y_{2}$ diperoleh sebesar $.358>.05$, maka dapat diambil kesimpulan bahwa terdapat hubungan yang linear antara Lingkungan KS-1 dengan pemenuhan hak bermain dan hak rekreasi pada anak usia 3-6 tahun di Kecamatan Dukuhseti.

Tabel 6. Data Hasil Analisi Deskriptif

\begin{tabular}{|c|c|c|c|}
\hline & $\begin{array}{c}\text { Lingkungan Keluarga Sejahtera } 1 \\
(\mathrm{KS}-1)\end{array}$ & Hak Bermain & Hak Rekreasi \\
\hline $\mathrm{N}$ & 48 & 48 & 48 \\
\hline Mean & 81.15 & 69.60 & 68.50 \\
\hline Minimum & 72 & 63 & 59 \\
\hline Maksimum & 97 & 79 & 82 \\
\hline
\end{tabular}

Tabel 7. Distribusi Frekuensi 
DOI: 10.31004 /obsesi.v6i3.1180

\begin{tabular}{llccc}
\hline Variabel & Interval Skor & Kategori & Frekuensi & Presentase \\
\hline KS-1 & $50<X \leq 63$ & Rendah & 0 & $0 \%$ \\
& $63<X \leq 76$ & Sedang & 13 & $27.083 \%$ \\
& $X>76$ & Tinggi & 35 & $72.917 \%$ \\
Hak Bermain & Jumlah & & 48 & $100 \%$ \\
& $46<X \leq 58$ & Rendah & 0 & $0 \%$ \\
& $58<X \leq 70$ & Sedang & 35 & $72.917 \%$ \\
& $X>70$ & Tinggi & 13 & $27.083 \%$ \\
Hak Rekreasi & Jumlah & & 48 & $100 \%$ \\
& $46<X \leq 58$ & Rendah & 0 & $0 \%$ \\
& $58<X \leq 70$ & Sedang & 35 & $72.917 \%$ \\
& $X>70$ & Tinggi & 13 & $27.083 \%$ \\
& Jumlah & & 48 & $100 \%$ \\
\hline
\end{tabular}

Tabel 8. Uji Normalitas

\begin{tabular}{cc}
\hline Pemenuhan Hak Dasar Anak & $a$ \\
\hline Lingkungan KS-1 dengan hak bermain & .162 \\
Lingkungan KS-1 dengan hak rekreasi & .071 \\
\hline
\end{tabular}

Tabel 9. Uji Linieritas

\begin{tabular}{cc}
\hline Pemenuhan Hak Dasar Anak & a \\
\hline Lingkungan KS-1 dengan hak bermain & .302 \\
Lingkungan KS-1 dengan hak rekreasi & .358 \\
\hline
\end{tabular}

\section{Pengaruh Lingkungan Keluarga Sejahtera 1 (KS-1) $(x)$ dengan Hak Bermain $\left(y_{1}\right)$}

Hasil hipotesis keluarga sejahtera 1 (KS-1) dengan hak bermain dapat dilihat melalui tabel 10. model summary, tabel 11. anova, dan tabel 12. Coefficients. Hasil dari Analisis menunjukkan bahwa lingkungan KS-1 dan hak bermain keduanya mampu menjelaskan $28 \%$ variasi dari Lingkungan KS-1 $\left(R^{2}=.285 ; \mathrm{F}(1,46)=18.349 ; p<.001\right)$. Lingkungan KS-1 secara signifikan mampu memperediksi pemenuhan hak bermain $(\beta=.594 ; p<.001)$. Lingkungan KS-1 mempunyai pengaruh positif terhadap pemenuhan hak bermain $(Y=42.924+0.329 X)$

Tabel 10. Model Summary

\begin{tabular}{lr}
\hline Model & R Square \\
\hline 1 & .285 \\
\hline
\end{tabular}

\section{Tabel 11. ANOVA ${ }^{\mathrm{a}}$}

\begin{tabular}{lrrrrr}
\hline Model & Df & F & Sig. & \\
\hline 1 Regression & 1 & 18.349 & & $.000^{\mathrm{b}}$ \\
Residual & 46 & & & \\
Total & 47 & & & \\
\hline
\end{tabular}

Tabel 12. Coefficients ${ }^{a}$

\begin{tabular}{|c|c|c|c|c|c|}
\hline \multirow[t]{2}{*}{ Model } & & $\begin{array}{c}\text { Unstandardized } \\
\text { Coefficients }\end{array}$ & $\begin{array}{c}\text { Standardized } \\
\text { Coefficients }\end{array}$ & $\mathrm{t}$ & Sig. \\
\hline & & $\mathrm{B}$ & Beta & & \\
\hline \multirow[t]{2}{*}{1} & (Constant) & 42.924 & & 6.871 & .000 \\
\hline & $\begin{array}{l}\text { Lingkunga } \\
\text { n Keluarga } \\
\text { Sejahtera } 1 \\
(\text { KS-1) }\end{array}$ & .329 & .534 & 4.284 & .000 \\
\hline
\end{tabular}

\section{Pembahasan}


Bermain adalah aktivitas yang anak lakukan secara terus menerus untuk mendapatkan kebahagiaan tanpa mempunyai target dan tuntutan yang harus tercapai (Hariwijaya, 2009). Bermain memiliki fungsi memberikan efek positif terhadap perkembangan anak(Azizah \& Kurniawati, 2013). Dengan kegiatan main, anak mempunyai peluang untuk mengembangkan kemampuan dan pemecahan masalah, sehingga anak memiliki kebebasan dan bisa belajar secara aktif dalam menjelajahi hal baru (Setyowati, 2018). Ada berbagai variasi kegiatan bermain menurut Hurlock (1993) yang dipengaruhi oleh faktor berikut: kesehatan, perkembangan motorik, inteligensi, jenis kelamin, lingkungan, taraf sosial ekonomi, jumlah waktu bebas, dan alat permainan. Berdasarkan hasil pengisian angket oleh responden penelitian ditemukan bahwa anak laki-laki ataupun perempuan mempunyai kesehatan yang baik dan normal. Anak-anak cenderung lebih memilih bermain aktif, dengan bermain aktif kesenangan akan timbul dari hal yang dilakukan anak secara bebas dan spontan yang membutuhkan lebih banyak energi seperti bereksperimen, menyelidiki, mencoba serta mengenal sesuatu yang menurut anak menarik.

Sebagai contoh dari hasil observasi penelitian bermain aktif yang dilakukan anak di lingkungan KS-1 yaitu berlari, bermain pura-pura (drama), membentuk dengan playdough, dan bermain musik. Sedangkan dalam bermain pasif jarang ditemui. Bermain pasif menurut Tedjasaputra (2001) merupakan permainan yang dilakukan anak secara tidak langsung, membutuhkan lebih sedikit energi seperti mendengarkan dongeng, menonton kartun, dan melihat temannya bermain. Pemilihan bermain anak sangat beragam karena anak mempunyai karakteristik yang berbeda tiap individu (Anderson KJ, Sanders P (Binagwaho et al., 2016)). Selaras dengan aspek kognitif anak, Jean Piaget (Mutiah, 2010) mengemukakan tahapan bermain pada anak umur 2-7 tahun dapat dikenali dengan tahap bermain simbolik/purapura. KS-1 sebagai responden penelitian kurang memahami perkembangan anak, ketika anak melakukan tanya-jawab, menjajal aneka kegiatan yang berkaitan dengan konsep angka, kuantitas, ruang dan sebagainya. Dalam hal bermain, keadaan lingkungan keluarga, rohani dan jasmaninya mempengaruhi pertumbuhan anak (Dalyono, 2009).

Pada saat bermain, anak akan beradaptasi dengan kejadian di sekitarnya. Anak akan belajar menilai akibat dari hasil permainan yang dilakukan sehingga terbentuk pengalaman sosial bagi anak (Fitri \& Waluyo, 2020). KS-1 sudah memiliki tempat bermain yang aman dan nyaman bagi anak walaupun terbilang kecil. Jenis permainan yang beragam dan edukatif masih jarang ditemukan karena terbatasnya pendapatan orangtua untuk menyukupi kebutuhan primer dalam keluarga. Adanya pendampingan orang tua dalam membantu menstimulasi aspek kognitif pada anak setiap bermain sudah ditemui dalam penelitian. Peran orang tua di rumah selama pandemi ini menjadi sangat penting dalam pemenuhan hak bermain karena hampir seluruh waktu anak di rumah sehingga jumlah waktu bermain pada anak sudah terpenuhi. Jumlah waktu bermain atau istilah the play years menurut Andre, dkk. (2017) adalah sebutan bagi anak dengan usia 2-6 tahun. Untuk memaksimalkan the play years, anak-anak disarankan bermain 5 jam dalam sehari. Waktu tersebut, semestinya diisi dengan aneka aktivitas main yang bervariasi, dan proposional antara bermain aktif dan pasif. Anak akan belajar tentang lingkungannya melalui kegiatan bermain. Ide-ide baru dan kreatifitas orang tua dalam merancang permainan sehingga anak tidak bosan di rumah dan dapat mengasah perkembangan anak menjadi tantangan tersendiri bagi lingkungan KS-1.

\section{Pengaruh Lingkungan Keluarga Sejahtera 1 (KS-1) $(x)$ dengan Hak Rekreasi $\left(y_{2}\right)$}

Hasil hipotesis keluarga sejahtera 1 (KS-1) dengan hak rekreasi dapat dilihat melalui tabel 13. model summary, tabel 14. anova, dan tabel 15. coefficients . 
DOI: 10.31004/obsesi.v6i3.1180

\begin{tabular}{lll}
\hline Model & R Square & \\
\hline 1 & .353 \\
\hline
\end{tabular}

\begin{tabular}{|c|c|c|}
\hline Model & Df & Sig. \\
\hline 1 Regression & 125.087 & $.000^{b}$ \\
\hline Residual & 46 & \\
\hline Total & 47 & \\
\hline
\end{tabular}

Tabel 14. Coefficients ${ }^{\mathrm{a}}$

\begin{tabular}{|c|c|c|c|c|c|}
\hline \multirow{2}{*}{\multicolumn{2}{|c|}{ Model }} & $\begin{array}{c}\text { Unstandardized } \\
\text { Coefficients }\end{array}$ & $\begin{array}{c}\text { Standardized } \\
\text { Coefficients }\end{array}$ & $\mathrm{t}$ & Sig. \\
\hline & & $\mathrm{B}$ & Beta & & \\
\hline & (Constant) & 33.313 & & 4.613 & .000 \\
\hline & $\begin{array}{l}\text { Lingkungan Keluarga } \\
\text { Sejahtera } 1 \text { (KS-1) }\end{array}$ & . 444 & .594 & 5.009 & .000 \\
\hline
\end{tabular}

Hasil analisis menunjukkan bahwa lingkungan KS-1 dan hak rekreasi keduanya mampu menjelaskan 35\% variasi dari Lingkungan KS-1 $\left(R^{2}=.353 ; \mathrm{F}(1,46)=25.087 ; p<.001\right)$. Lingkungan KS-1 secara signifikan mampu memperediksi pemenuhan hak rekreasi $(\beta=.534$ $; \mathrm{p}<.001)$. Lingkungan keluarga berpengaruh positif terhadap pemenuhan hak rekreasi $(Y=$ $33.313+0,444 X)$.

Menurut BKKBN dalam Puspita, dkk. (2014) pengertian KS-1 dalam kategori keluarga sejahtera disebutkan bahwa, "Keluarga sejahtera tahap I adalah keluarga-keluarga yang telah dapat memenuhi kebutuhan dasar, tetapi belum dapat memenuhi kebutuhan sosial psikologisnya". Kebutuhan dasar meliputi pangan, sandang, dan papan. Dalam hal ini, rekreasi merupakan jenis kebutuhan berdasarkan sifat, yakni kebutuhan rohani. Kebutuhan rohani merupakan kebutuhan yang dimiliki seseorang untuk memperoleh kebahagian bagi jiwa. Salah satu hak yang juga merupakan kebutuhan dasar anak adalah kebutuhan akan rekreasi. Rekreasi yaitu kegiatan yang dilakukan untuk penyegaran kembali jasmani dan rohani seseorang serta sebagai pelengkap dari kerja(Rosdiani, 2016). Anak butuh penyegaran sama halnya dengan orang tua. Faktor yang mempengaruhi rekreasi meliputi adaptasi, kebersamaan, waktu luang, dan kreatifitas.

Berdasarkan hasil dari pengisian angket hak rekreasi oleh responden penelitian diperoleh hasil bahwa melalui rekreasi dapat menambah pengetahuan anak mengenai hal-hal yang baru dilihat, diraba ataupun dirasakan oleh anak serta dapat menambah perbendaharaan kata pada anak. Orang tua KS-1 cenderung lebih memilih rekreasi di alam terbuka karena murah dan dapat memberikan pengetahuan terkait cara anak agar dapat lebih menghargai alam. Anak akan mendapatkan pengalaman baru yang sebelumnya belum diketahui seperti keanekaragaman budaya dari sebuah objek wisata dan eksplorasi lingkungan. Selain itu, rekreasi di alam dapat meningkatkan rasa percaya diri anak karena anak dapat berlatih berkomunikasi dengan orang-orang baru dan bermain bersama, meningkatkan kreativitas dengan benda-benda yang ada di sekelilingnya, meningkatkan daya tahan tubuh anak melalui olahraga dan dapat membantu anak beradaptasi dengan lingkungan baru terkait seni dan budaya yang ada. Sesuai dengan penelitian dari Ozen (Andre et al., 2017) bahwa rekreasi di luar ruang telah terbukti memiliki efek positif pada tingkat dukungan sosial anak. Anak akan memiliki lebih banyak teman dan berpengaruh terhadap penurunan level kecemasan sosial pada anak.

Selain itu, dari hasil observasi pemilihan wisata edukasi oleh KS-1 hanya sedikit, dikarenakan letak Kecamatan Dukuhseti yang mempunyai jarak 1 jam dari pusat kota. Rekreasi juga dapat merangsang keberanian anak. Keberanian merupakan hal yang didapatkan ketika anak melakukan aktivitas. Berani memulai sesuatu yang baru merupakan awal dari rasa penasaran anak terkait hal-hal baru. Bagi orang tua KS-1 rekreasi dapat menjadi momen untuk melatih keberanian, komunikasi yang lebih baik dan hangat dengan anak, tetapi hal ini sulit dilaksanakan karena pendapatan yang hanya cukup untuk kebutuhan pokok. Keluarga KS-1 lebih cenderung mendefinisikan bahwa aktivitas rekreasi selalu 
membutuhkan banyak uang. Padahal aktivitas yang membahagiakan anak bersifat rekreatif, misalnya membaca buku sebelum tidur dan menonton televise/film merupakan hiburan berkesan untuk anak, bercocok tanam, dan memasak makanan kesukaan merupakan hiburan berarti bagi anak yang dapat digunakan sebagai sarana pemenuhan hak anak dalam mendapatkan rekreasi.

Anak usia dini memang seharusnya diisi dengan hal-hal yang menyenangkan. Rekreasi dapat menjadi salah satu kenangan masa kecil bagi anak yang akan terekam dalam memori kecil, energi positif akan tetap dirasakan anak walaupun kegiatan rekreasi telah usai. KS-1 merencanakan liburan dengan jadwal dan pemilihan tempat ataupun kegiatan yang didiskusikan terlebih dahulu bersama anak membuat anak merasa dihargai atas keputusan yang disepakati bersama. Orang tua harus memperhatikan usia anak dalam menentukan tempat atau kegiatan rekreasi yang aman dan sesuai usia anak. Pada saat pandemi seperti ini, pemenuhan hak mendapatkan rekreasi bagi anak dilakukan di sekitar rumah yang tidak terdapat banyak orang atau kerumunan orang. Olahraga di halaman rumah, membacakan buku kesukaan anak setiap malam dan berkebun bersama menjadi alternatif rekreasi di masa pandemi.

\section{Faktor Penghambat dan Pendukung Lingkungan Keluarga Sejahtera I (KS-I) Terhadap Pemenuhan Hak Bermain dan Hak Rekreasi di Kecamatan Dukuhseti}

Adapun faktor penghambat lingkungan KS-1 terhadap pemenuhan hak anak meliputi: 1) Cara orang tua mendidik. Berdasarkan hasil pengisian angket ditemukan bahwa terdapat responden lingkungan KS-1 yang belum mengetahui pemenuhan hak-hak dasar anak termasuk hak bermain dan hak rekreasi tetapi sudah dapat memenuhi hak dasar bermain dan rekreasi. Kurangnya pengetahuan tersebut membuat orang tua tidak paham terhadap tahap perkembangan anak menurut usia, anak dibiarkan bermain apa saja yang anak inginkan asalkan anak diam. Orang tua tidak menyesuaikan jenis permainan dan pemilihan tempat rekreasi berdasarkan tahapan perkembangan anak tetapi hanya berdasarkan pengalaman orangtua masa kecil, 2) Kondisi ekonomi orang tua. Lingkungan KS-1 dalam pemenuhan hak bermain, orangtua hanya membelikan mainan anak ketika mempunyai uang lebih karena orangtua tidak merencanakan tabungan untuk membeli alat permainan. Sedangkan dalam pemenuhan hak rekreasi, orang tua cenderung beranggapan bahwa rekreasi berorientasi dengan perjalanan jauh dan membutuhkan biaya mahal, selain itu terdapat orang tua yang hanya memfasilitasi hak rekreasi anak ketika ada jadwal rekreasi dari sekolah saja karena orang tua tidak menyiapkan tabungan untuk rekreasi. Penghasilan dan pendapatan KS-1 hanya mampu menyukupi kebutuhan primer dan sekunder, sedangkan alat permainan dan rekreasi masuk dalam kategori kebutuhan tersier, dan 3) Latar belakang kebudayaan. Orangtua yang berpendidikan tinggi mempunyai pengalaman yang cukup luas dalam mendidik anak agar dapat mencapai tugas perkembangan secara utuh dan optimal sesuai tahapan usia dan memenuhi hak-hak dasar anak. Sedangkan, responden penelitian ini adalah lingkungan KS-1 yang sebagian besar melupakan lulusan SD yang mempunyai pengetahuan terbatas.

Sedangkan faktor pendukung meliputi : 1) Interaksi antar anggota keluarga. Adanya interaksi dipengaruhi oleh individu, tujuan, dan hubungan yang baik di dalam lingkungan keluarga akan memberikan pemenuhan kebutuhan anak semakin mudah dan dapat mengasah perkembangan dengan optimal. Interaksi lingkungan KS-1 terjalin harmonis, peraturan dalam keluarga ditaati oleh semua anggota keluarga, mengajak anak berdiskusi sederhana seperti mendiskusikan pemilihan tempat/ kegiatan yang akan dilaksanakan bersama, menyusun aturan main bersama dan terjadi interaksi yang menyenangkan antar anggota keluarga, 2) Suasana rumah. Suasana rumah merupakan keadaan yang dapat mempengaruhi keluarga. Anak mampu belajar dari suasana rumah yang harmonis, hening dan nyaman sehingga anak menyukai lingkungan rumahnya dan pemberian stimulasi anak dapat optimal. Orangtua KS-1 selalu menjaga kebersihan tempat bermain anak agar tetap 
nyaman, menstimulasi anak membereskan barang yang telah dipakai, serta orangtua memberi contoh anak dalam menjaga hubungan yang baik dengan teman dan tetangga, dan 3) Perhatian orang tua. Ibu yang tidak bekerja memiliki waktu luang yang cukup untuk anak dan sebaliknya ibu yang bekerja cenderung memiliki waktu yang terbatas. Orang tua terutama ibu berperan menemani, memberikan perhatian, serta memberikan stimulasi ketika anak bermain dan rekreasi. Sebagian besar responden penelitian KS-1 adalah ibu rumah tangga sehingga memiliki waktu yang cukup untuk mencurahkan perhatian kepada anak.

Selain faktor-faktor yang telah disebutkan di atas, sebagaimana teori yang dinyatakan oleh Barnadib (2002) lingkungan keluarga yang harmonis (tidak terjadi perceraian ataupun berpoligami) memudahkan anak mendapatkan hak-hak dasarnya. Lingkungan keluarga merupakan tempat pertama pemenuhan hak-hak dasar anak karena keluarga merupakan inti dari organisasi sosial lainnya. Pemenuhan hak-hak dasar anak di Kabupaten/Kota terjadi apabila seluruh kecamatan, desa/kelurahan, semua RW/RT, dan keluarga sudah layak anak.

\section{SIMPULAN}

Pemenuhan hak bermain di lingkungan KS-1 berperan terhadap pengalaman main yang menyenangkan. Pemenuhan hak rekreasi menambah pengetahuan, anak mudah beradaptasi, meningkatkan rasa percaya diri, kreatif. Faktor penghambat: cara orang tua mendidik, kondisi ekonomi, latar belakang kebudayaan. Faktor pendukung: interaksi antar anggota keluarga, suasana rumah, perhatian orang tua. Perlu adanya kebijakan yang harus diperhatikan terkait pemenuhan hak-hak dasar anak, seperti halnya melalui dana desa membangun fasilitas umum bermain dan rekreasi yang diakses gratis oleh masyarakat. Penelitian ini tidak sampai membahas pengaruh eksternal lain selain lingkungan KS-1 yang dapat mempengaruhi hak bermain dan hak rekreasi, semoga dapat dijadikan peluang bagi peneliti selanjutnya.

\section{UCAPAN TERIMA KASIH}

Penulis mengucapkan terimakasih kepada semua pihak yang telah membantu dalam penelitian ini. Secara khusus penulis mengucapkan terimakasih kepada kepala desa seKecamatan Dukuhseti dan anggota PKK Kecamatan Dukuhseti yang telah banyak membantu pelaksanaan penelitian. Ucapan terimakasih juga penulis sampaikan kepada PGPAUD, Universitas Negeri Semarang yang memberikan dukungan hingga penelitian ini selesai.

\section{DAFTAR PUSTAKA}

Ahmadi, A. (2007). Sosiologi Pendidikan. Rineka Cipta.

Ali, M., \& Prima, E. (2020). Indonesian Journal of Early Childhood Democratic Values in Early Care of Children in A Children Garden. 9(2), 98-104. https:/ / doi.org/10.15294/ijeces.v9i2.40701

Andre, E. K., Williams, N., Schwartz, F., \& Bullard, C. (2017). Benefits of Campus Outdoor Recreation Programs: A Review of the Literature. Journal of Outdoor Recreation, Education, and Leadership, 9(1), 15-25. https://doi.org/10.18666/JOREL-2017-V9-I1$\underline{7491}$

Azizah, N., \& Kurniawati, Y. (2013). Tingkat Keterampilan Berbicara Ditinjau Dari Metode Bermain Peran Pada Anak Usia 5-6 Tahun. Indonesian Journal of Early Childhood Education Studies, 2(2), 50-57. https://doi.org/10.15294/ijeces.v2i2.9241

Babić, M. M., Tkalec, S., \& Cheatham, L. P. (2018). The right to education for children with disabilities from the earliest age. Croatian Journal of Education, 20(1), 233-263. https://doi.org/10.15516/cje.v20i1.2494

Badan Pusat Statistik Kabupaten Pati. (2019). Kecamatan Dukuhseti Dalam Angka 2019. Badan Pusat Statistik Kabupaten Pati.

Barnadib, I. (2002). Filsafat Pendidikan. Adicita Karya Nusa. 
Binagwaho, A., Scott, K. W., \& Harward, S. H. (2016). Early childhood development in Rwanda: A policy analysis of the human rights legal framework. BMC International Health and Human Rights, 16(1), 1-5. https:/ / doi.org/10.1186/s12914-016-0076-0

BKKBN. (2011). Batasan dan Pengertian MDK. Pemutakhiran Data Keluarga. http://aplikasi.bkkbn.go.id/mdk/BatasanMDK.aspx

Dalyono, M. (2009). Psikologi Pendidikan. Rineka Cipta.

Dewi, S. M. (2011). Transformasi Kudus Sebagai Kota Layak Anak ( Tinjauan atas Pemenuhan Hak Sipil dan Partisipasi ). Muwazah, 3(1), 398-410.

Fitri, S. N., \& Waluyo, E. (2020). Early Childhood Education Papers Implementation of Ksatria Story Book in Embedding Leadership Character Values in Children 5-6 Years Old. Jurnal Belia, 9(1), 7-12. https://doi.org/10.15294/belia.v9i1.28381

Gunarsa, S. D. (2008). Psikologi Anak: Psikologi Perkembangan Anak dan Remaja. PT BPK Gunung Mulia.

Hariwijaya. (2009). PAUD Melejitkan Potensi Anak dengan Pendidikan Sejak Dini. Mahadika Publicity.

Hidajat, E. (2002). Aku Anak Dunia (Bacaan Hak-hak Anak bagi Anak). Yayasan Aulia Jakarta. Hurlock, E. B. (1993). Psikologi Perkembangan: Suatu Pendekatan Sepanjang Rentang Kehidupan (edisi ke lima). Erlangga.

Indriati, N. Y., Wahyuningsih, K. K., S, S., \& S, S. (2018). Perlindungan dan Pemenuhan Hak Anak (Studi Tentang Orangtua Sebagai Buruh Migran Di Kabupaten Banyumas). Mimbar Hukum - Fakultas Hukum Universitas Gadjah Mada, 29(3), 474. https://doi.org/10.22146/jmh.24315

KEMDIKBUD. (2019). Temukan Informasi Sekolah di seluruh Indonesia. Sekolah Kita. http:/ / sekolah.data.kemdikbud.go.id/

KEMENPPPA. (2020). Sejarah Kemenpppa Republik Indonesia. Kementerian Pemberdayaan Perempuan Dan Perlindungan Anak Republik Indonesia. www.kemenpppa.go.id

Kementerian Pemberdayaan Perempuan dan Perlindungan Anak dan Badan Pusat Statistik. (2019). Profil Anak Indonesia Tahun 2019. Kementerian Pemerdayaan Perempuan Dan Perlindungan Anak (KEMENPPPA), 378. https://www.kemenpppa.go.id/lib/uploads/list/15242-profil-anak-indonesia_2019.pdf

Kurnia, R. (2012). Konsepsi Bermain dalam menumbuhkan Kreativitas Pada Anak Usia Dini. Jurnal Educhild : Pendidikan dan Sosial. 01(1), 77-85.

Latiana, L. (2019). Buku Ajar Pendidikan Anak Dalam Keluarga. PGPAUD UNNES.

Lehrl, S., Evangelou, M., \& Sammons, P. (2020). The Home Learning Environment and Its Role in Shaping Children's Educational Development. School Effectiveness and School Improvement, 31(1), 1-6. https:// doi.org/10.1080/09243453.2020.1693487

Mutiah, D. (2010). Psikologi Bermain Anak Usia Dini. Kencana.

Nuryani, S. (2015). Studi Deskriptif Penanaman Nilai Moral Pada Anak Usia Dini di Lingkungan Lokalisasi Sunan Kuning Kelurahan Kalibanteng Kulon Kota Semarang. Belia, 4(2), 72-78. https:/ / doi.org/10.15294/belia.v4i2.7546

Orth, U. (2018). The family environment in early childhood has a long-term effect on selfesteem: A longitudinal study from birth to age 27 years. In Journal of Personality and Social Psychology (Vol. 114, Issue 4, pp. 637-655). American Psychological Association. https://doi.org/10.1037/pspp0000143

Pratama, D., Hidayah, R., \& Hargiyansari, T. (2016). Peran pendidik dalam menumbuhkan perilaku prososial anak dengan media permainan tradisional. Seminar Nasional Hasil Penelitian Kepada Masyarakat UNIPMA, 20-23.

Puspita, Dini; Suparti; Wilandari, Y. (2014). Klasifikasi Tingkat Keluarga Sejahtera dengan Menggunakan Metode Regresi Logistik Ordinal dan Fuzzy K-Nearest Neighbor (Studi Kasus Kabupaten Temanggung Tahun 2013). Jurnal Gaussian, 3(4), 645-653.

Rosdiani, D. (2016). Pendidikan Rekreasi. Alfabeta. 
Setyowati, N. D. (2018). Penerapan Permainan Kreatif Mencari Harta Karun Untuk Meningkatkan Kemampuan Memecahkan Masalah Pada Anak Kelompok B Di Taman Kanak-Kanak Mm . Novita Dwi Setyowati Abstrak Aspek perkembangan kognitif dalam memecahkan masalah adalah aspek utama yang harus. Jurnal Pinus, 3(2), 111117. https://doi.org/10.29407/pn.v3i2.11872

Shah, S. A., Shah, S. M. H., \& Ishfaq, U. (2018). Violations of Basic Children Rights at Elementary Level Education. Global Social Sciences Review, III(IV), 114-126. https:// doi.org/10.31703/gssr.2018(III-IV).08

Slameto. (2003). Belajar dan Faktor-faktor yang Mempengaruhinya. Rineka Cipta.

Sulistiowati, R., Prihantika, I., Atika, D. B., \& Sari, Y. R. (2018). Implementasi Kebijakan Kabupaten Layak Anak Di Kabupaten Pringsewu. Spirit Publik, 13(2), 27-46. https://doi.org/10.20961/sp.v13i2.24874

Tedjasaputra, M. (2001). Bermain, Mainan, dan Permainan untuk Pendidikan Usia Dini. Gramedia Widiasarana Indonesia.

Thalib, M. C. (2020). Refleksi Perlindungan Hak Anak Butuh Kasih di Kota Gorontalo. Jurnal Obsesi : Jurnal Pendidikan Anak Usia Dini, 5(1), 566. https:// doi.org/10.31004/obsesi.v5i1.672

UNICEF. (2018). Konvensi Hak Anak: Versi Anak-Anak. UNICEF Indonesia. https://www.unicef.org/indonesia/id/konvensi-hak-anak-versi-anak-anak

Wardani, R. K., \& Hasanah, I. (2015). Pemenuhan Hak Anak dalam Keluarga Poligami (Children Right Fulfillment in Polygamy Family). Jurnal Perempuan Dan Anak, 1(23), 1-6. https://doi.org/10.22219/jpa.v1i1.2744

Widyatama, I. G. N., \& Suwena, I. K. (2017). Pengetahuan Dasar Ilmu Pariwisata. Bali: Pustaka Larasan. Pustaka Larasan. 